\title{
Wind of Change
}

\section{Michel Matter}

Dr, Vice-président de la FMH, responsable du département Prestations et développement professionnel

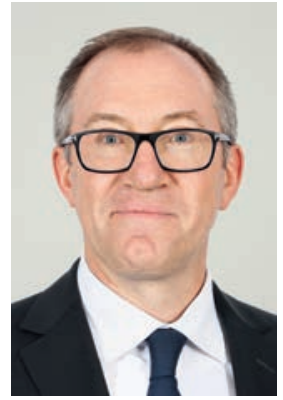

En 1990, Klaus Meine, leader du groupe de hard rock allemand Scorpions, a composé une chanson, Wind of Change, pour exprimer les changements politiques du début des années 90. Dans le même temps est née une nouvelle génération, les Millennials, qui aime à balayer les codes du passé. Cette génération bouscule ce qui est établi et surtout interroge. Elle recherche une morale forte, une éthique claire et se préoccupe de son environnement qu'il soit privé, professionnel ou planétaire.

Le monde des soins est largement féminin. Le sexisme existe et commence à faire débat sous l'impulsion de cette génération qui impose la libération de la parole qui seule permet la transparence. Les hôpitaux et les centres médicaux n'échappent pas à ce mouvement. Ce qui a été pendant trop longtemps communément toléré ou caché ne peut plus l'être. Le sexisme, comme le racisme ou tout

\section{Le sexisme existe et commence à faire débat} sous l'impulsion d'une génération qui impose la libération de la parole.

manque de respect en raison de l'identité de l'autre, ne peut avoir sa place dans nos murs. Les remarques sexistes, les regards appuyés ou les contacts furtifs doivent être non seulement bannis mais également dénoncés. Et cela entre collègues, entre professionnels de la santé mais également de la part des patients. Ne nous méprenons pas, l'immense majorité du personnel et des patients ont un comportement correct et irréprochable. Cependant, comme pour le hooliganisme, le racisme ou le sexisme, quelques-uns se permettent de franchir la ligne rouge. Cela est intolérable. Il faut avoir le courage de dire STOP.

Les professionnels de la santé, quel que soit leur métier, expriment de plus en plus une réelle souffrance. Une souffrance liée à une perte de sens des professions médicales et paramédicales et à un manque de reconnaissance, à des surcharges administratives mais aussi à un manque de respect du travail accompli. Le sexisme ajoute de la souffrance à la souffrance. Il est donc essentiel qu'un lien fort soit établi entre la SWIMSA,

Les remarques sexistes, les regards appuyés ou les contacts furtifs doivent être non seulement bannis mais également dénoncés.

l'ASMAC, H+ et la FMH afin de proposer une Charte qui serait remise à tout médecin, tout professionnel de la santé mais également à tout patient entrant dans une institution médicale.

A Lausanne, un collectif, CLASH (Collectif de Lutte contre les Attitudes Sexistes en milieu Hospitalier), a été créé il y a un an par des étudiants en médecine afin de sensibiliser et de communiquer autour de la problématique du sexisme et du harcèlement en milieu hospitalier. L'émission Vacarme de la RTS vient de consacrer une semaine à ce thème (Sexisme à l'hôpital, une maladie chronique?), avec des témoignages forts. Un collègue, Martin Winckler, auteur de La maladie de Sachs, vient de publier un livre, L'Ecole des soignantes, qui évoque un hôpital du futur qui soigne sans discrimination et avec bienveillance.

Le vent du changement. 